\title{
تقويم تعليم قواعد اللغة بكتاب أمثلتي في ضوء المدخل الإتقاني في معهد دار الفلاح
}

\author{
Moh Irhas
}

mohirhas@iainkudus.ac.id

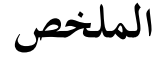

هذا البحث يبحث عن تقويم برنامج أمثلتي في معهد دار الفلاح الذي ينفذ تعليم قواعد اللغة باستخدام كتاب أمثلتي على المدخل الإتقاني. ويهدف هذا البحث إلى ما يلي: (1) لمعرفة تخطيط تعليم قواعد اللغة بكتاب أمثلتي في ضوء المدخل الإتقاني، ب) لمعرفة تنفيذ تعليم قواعد إلمدي اللغة بكتاب أمثلتي في ضوء المدخل الإتقاني، ؟) لمعرفة نتائج تعليم قواعد اللغة بكتاب أمثلتي في ضوء المدخل الإتقاني. استخدم الباحث في هذا البحث المدخل المزيج، ونوعه هو البحث التقويمي. أما الأساليب لجمع البيانات فهي الملاحظة، والمقابلة، والإستبيان، والتوثيق. ونتائج هذا البحث على ما يلي: () تخطيط تعليم قواعد اللغة في برنامج أمثلتي يعتبر جيدا، بال ) تعليم

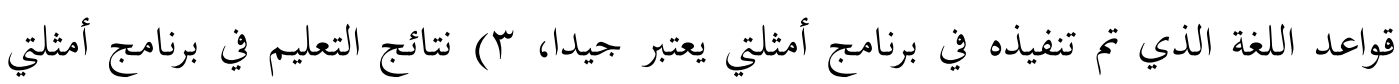

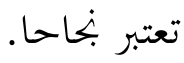

الكلمات المفتاحية : التقويم، تعليم قواعد اللغة، كتاب أمثلتي، المدخل الإتقاني 


\begin{abstract}
ABSTRAK
Penelitian ini membahas evaluasi program Amtsilati pondok Darul Falah dalam melaksanakan pembelajaran kaidah bahasa Arab menggunakan kitab Amtsilati dengan pendekatan belajar tuntas. Adapun tujuan penelitian ini adalah: 1. Untuk mengetahui perencanaan pembelajaran kaidah bahasa Arab menggunakan kitab Amtsilati dengan pendekatan belajar tuntas, 2. Untuk mengetahui pelaksanaan pembelajaran kaidah bahasa Arab menggunakan kitab Amtsilati dengan pendekatan belajar tuntas, 3. Untuk mengetahui hasil pembelajaran kaidah bahasa Arab menggunakan kitab Amtsilati dengan pendekatan belajar tuntas, 4. Untuk mengetahui kendala-kendala pembelajaran kaidah bahasa Arab menggunakan kitab Amtsilati dengan pendekatan belajar tuntas serta upaya mengatasinya. Penelitian ini menggunakan pendekatan campuran dengan jenis penelitian evaluatif. Metode pengumpulan data menggunakan observasi, interview, angket dan dokumentasi. Adapun hasil penelitian : 1. Perencanaan pembelajaran kaidah bahasa Arab di program Amtsilati sudah berjalan dengan baik, 2. Pelaksanaan pembelajaran kaidah bahasa Arab di program Amtsilati sudah berjalan dengan baik, 3 . Hasil belajar siswa di program Amtsilati dapat dikatakan sudah berhasil.
\end{abstract}

Kata kunci: Evaluasi, Pembelajaran Kaidah Bahasa Arab, Kitab Amtsilati, Pendekatan Belajar Tuntas.

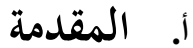

من التربية الدينية المطورة في المعاهد هي تدريس كتب التراث، وهي كتاب يكتب

بالأحرف العربية يستخدم لتعمق العلوم الدينية. وقد تعتبر بالكتب الصفراء لأن لون

قرطاس صفحاتها أصفر. ولفهم مضمون كتب التراث، على التلاميذ أن يستوعبوا القواعد

العربية. إذ تعليم القواعد العربية له علاقة قوية في فهم العلوم الدّينية لاسيما في تسهيل

الفهم على نصوص القرآن والحديث والكتب الدّينية يعني كتب التراث. (أحمد، جVT )

( I $\vee \wedge$

فتعليم القواعد العربية هو أمر أساسي لتقويم النطق وتصديقه وتسليمه من اللحن

في الكالام. لأن التلاميذ الذين يرتبون الكلمة بدون علم النحو لن يفهموا معناها. ولذا 
اتفق العلماء على أن علم القواعد العربية وسيلة لفهم اللغة العربية فبدونه يكون معنى اللغة غير واضح. ومما يؤسف له، أن تعليم قواعد اللغة في معظم المعاهد الإسلامية التقليدية يستخدم الكتب التراثية نحو الألفية لابن مالك والمتممة والأجرومية والكيلاين والنظم العمريطي كالمرجع الأساسي. والطريقة المستخدمة في تدريسها طريقة تقليدية، وهي طريقة الاينة bandongan sorogan مالك والمتممة والأجرومية، وكذلك حفظ الكتب الأخرى المدروسة، حتى أن الطلاب

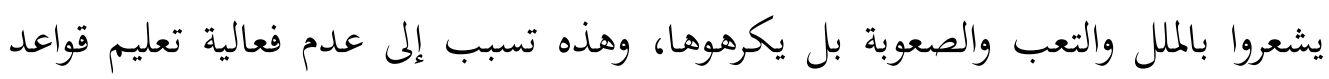
اللغة العربية.

ويقوم معهد دار الفلاح باغسري جفارا البرنامج الخاص في تدريس قواعد اللغة

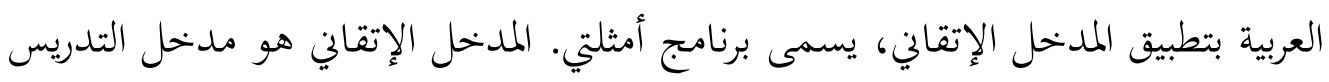

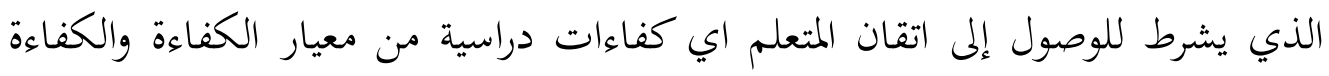

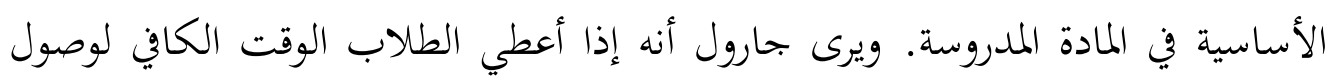
إلى مستوى الإتقان، ويستخدمون الوقت الذي يحتاجونه لتعلم، فسيحصلون على درجة إنها إتقان الكفاءة. بل إلا يعطى الوقت الكافي ولايستخدمون الوقت الذي يكتاجونه لتعلم تماما، فتنقص درجة إتقان كفاءقم. أما تطبيق عملية التعليم الإتقاني بالخطوات التالية: ا ـ تحديد الأهداف التعليمية المطلوبة عامة كانت وخاصة.

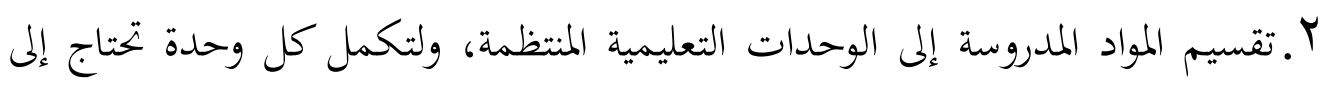

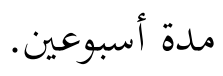
"؟ تنفيذ عملية التعليم فصليا مناسبا بتتابع الوحدة التعليمية المدروسة. 
ع. تطبيق الإختبار البنائي على التلاميذ في فاية تدريس الوحدات قبل الإنتقال إلى تدريس

وحدة جديدة.

0. بناء على نتائج الإختبار البنائي، فإن الطلاب الذين لم يصلوا الم درجة الاتقان

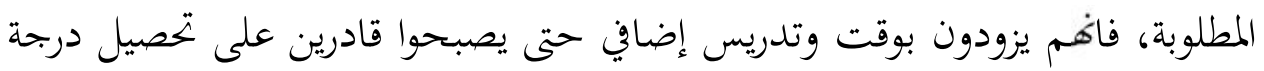

$$
\text { الاتقان في الاختبار. }
$$

T. بعد حصل كل تلميذ أو أكثرهم الى درجة الاتقان المحدة، فينتقل التدريس إلى الوحدة

$$
\text { الأخرى. }
$$

V.تكرار خطوات إجراءات تدريس كل وحدة من الوحدات التعليمية حتى ينتهي تقديمها

$$
\text { جميعا. }
$$

^. بعد إنتهاء كل وحدة، يطبق الإختبار النهائي المشتمل على كل وحدة من الوحدات

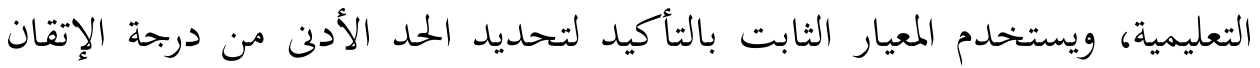

$$
\text { حول • ـ - . 9\% من الأهداف المحددة. }
$$

(Majid, 2014: 159-161)

وكان تدريس القواعد العربية في هذا البرنامج يجري باستخدام كتاب أمثلتي، وهو

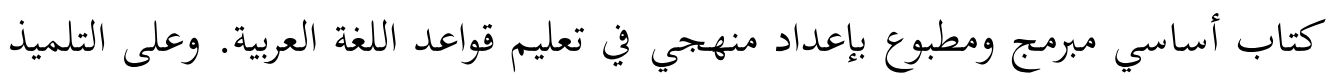

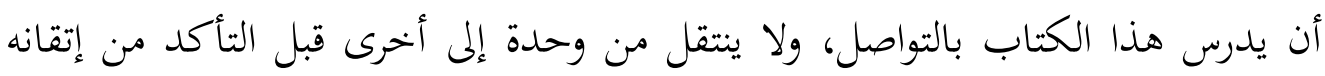

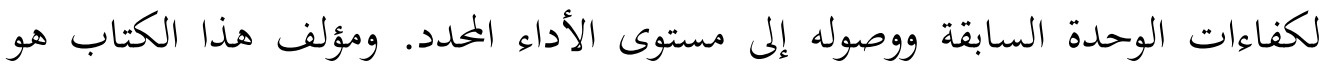
أستاذ توفيق الحاكم الحاج، وهو مؤسس المعهد دار الفلاح. يتم برنامج أمثلتي العمليات التعليمية على ما يلي:

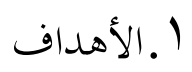

من أهم العناصر في عمليات التعليم هي الأهداف التعليمية. ولأجل تحقيق

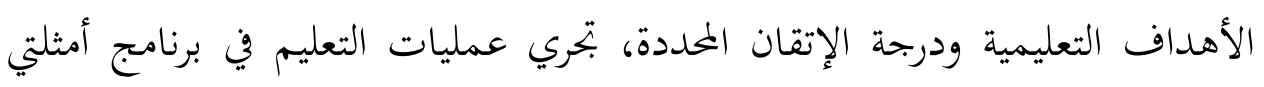




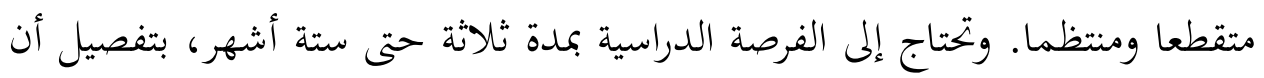

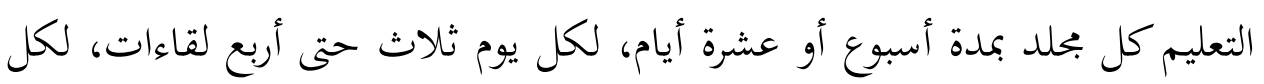
لقاء 0 ؛ دقائق. r

يستخدم هذا البرنامج كتاب أمثلتي كالكتاب الأساسية لتعليم قواعد اللغة، ويكتوي على مادة مبربحة ويصمم بإعداد منهجي حيث يتعلمها التلاميذ متواصلا

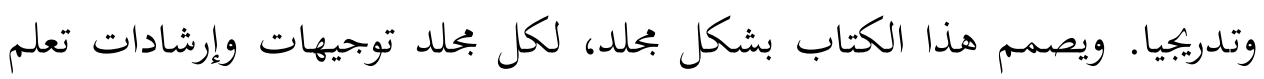
الكتاب حيث يتعلمه التلاميذ حسب فروق كفاءاقم الفردية.

يتكون كتاب أمثلتي على خمسة بحلدات، يحتوى البحلد الأول على أربعة أبواب

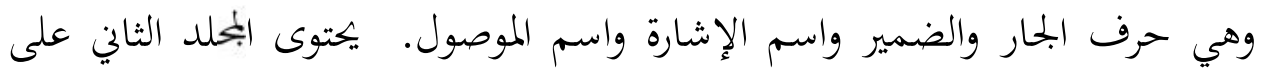

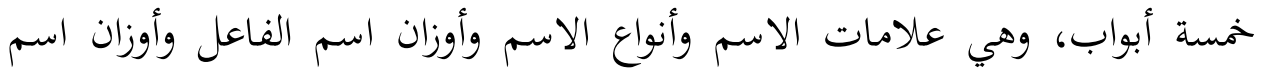

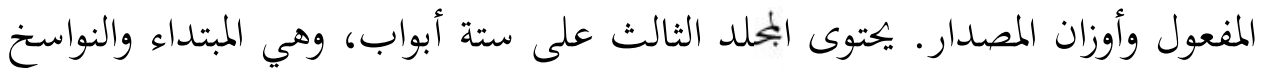

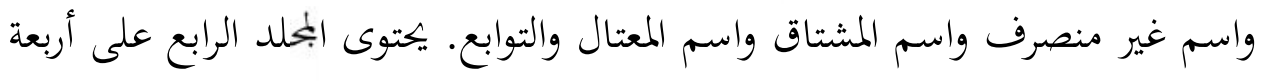

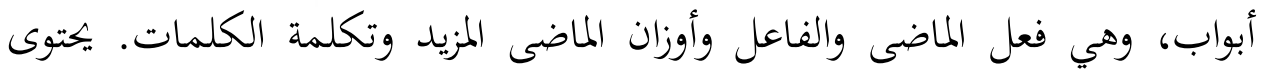
البحلد الخامس على ستة أبواب، وهي فعل المضارع وأوزان المضارع المزيد وعوامل المانل النواصب وعوامل الجوازم وفعل الأمر والمهمات.

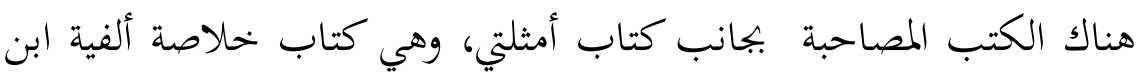

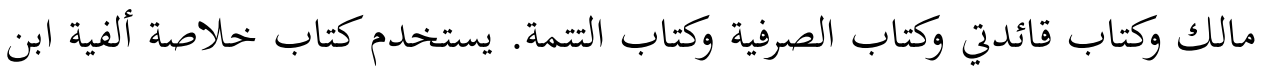

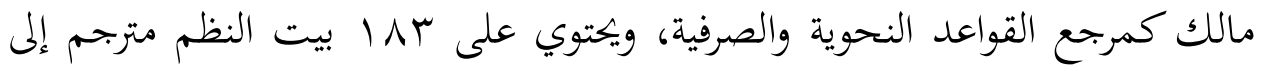

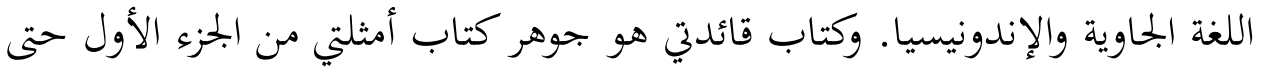
الأخير وإرشادات استخدام النظم في كتاب الخلاصة. أما كتاب الصرفية يعتبر

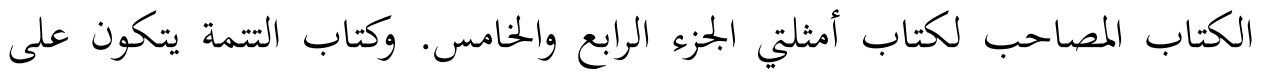


بحلدين، ويعتبر أهم الكتب المصاحبة لأنه يختوي على تطبيق القواعد التي درسها التلاميذ في كتاب أمثلتي إلى الجمل البحودة.

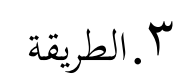

العناصر التى تؤثر فن العملية التعلمية ويعتمد عليها المدرسون فن القاء الدروس

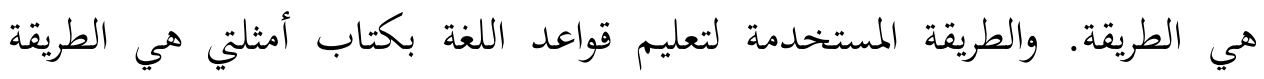

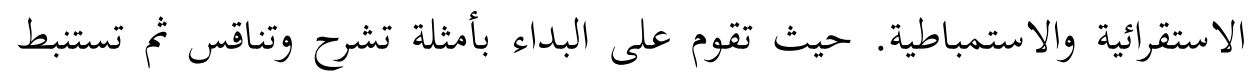

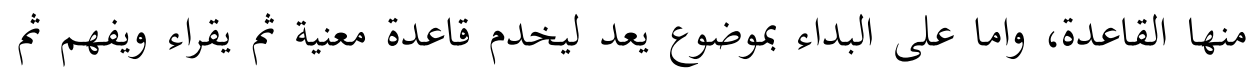
تناقس عباراته الخادمة لقاعدة تستنبط منها.

وأما خطوات اجراءت تعليم قواعد اللغة العربية بكتاب أمثلتي كما يلي:

(Taufiq, 2003: muqaddimah)

$$
\text { ( ) يقرأ المعلم الفاتحة لمؤلف الكتاب وناشره }
$$

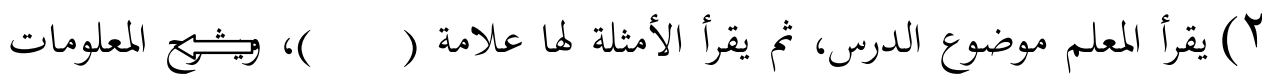

$$
\text { بقدر الحاجة }
$$

ب) يقرأ الطلاب الأمثلة من الأيات القرأنية مرتين جماعة. تقرأ الأمثلة في مرة أولى

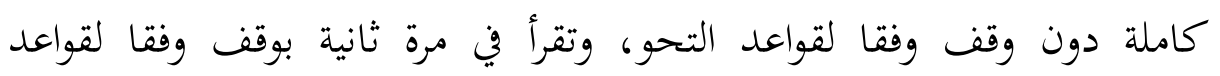

$$
\text { التجويد }
$$

ع) يكرر الطاب قراءة المعلومات أدن الأمثلة وأساسها النظمي

$$
\text { ( ) يقرأ الطلاب اللآية إلى أسفلها }
$$

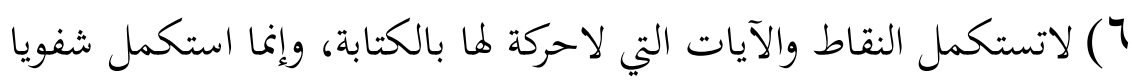

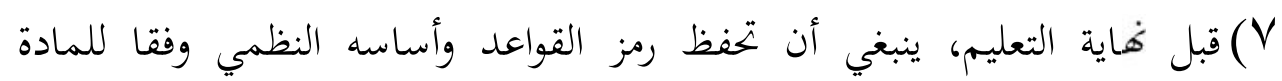

$$
\text { الدراسية المتعلمة }
$$

^) عند ما يبدأ التعليم، ينبغى أن تكررهما حسب الحاجة 
9) لمعرفة نوعية كتابة الطلاب، يكمن توفير الواجبة المنزلية أو الوظيفة لكتابة المادة

المدروسة

• (1) إذا قدر الطلاب على حفظ المفردات، فحفظها أفضل

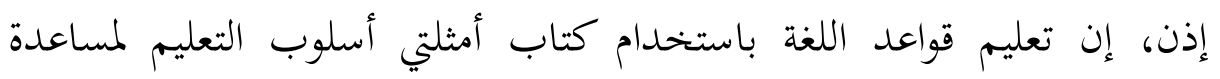

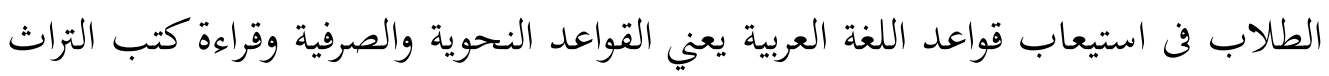

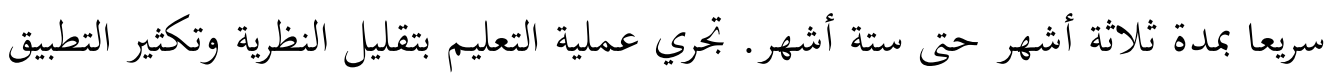

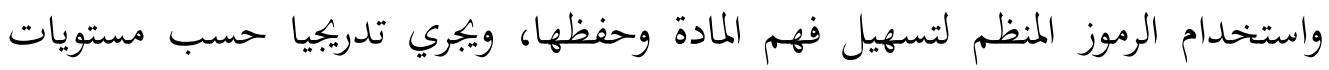

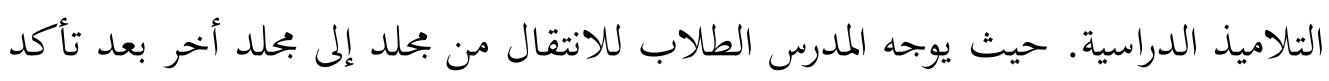

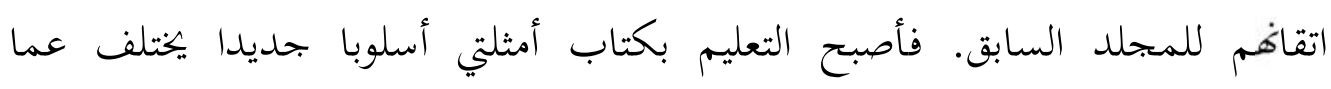
استخدمه معاهد أو مدارس أو جامعات في هذا البلد.

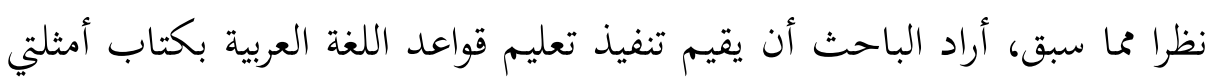

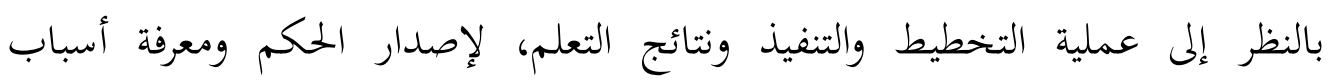

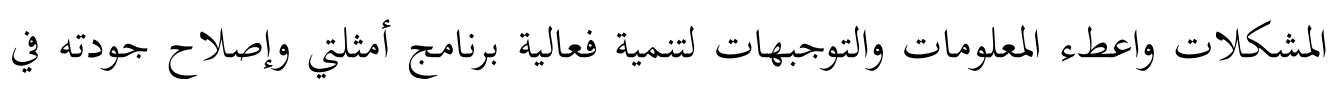
تعليم قواعد اللغة العربية.

بناء من المقدمة السابقة، يقدم الباحث أسئلة البحث كما يلي: (1) ) كيف تخطيط

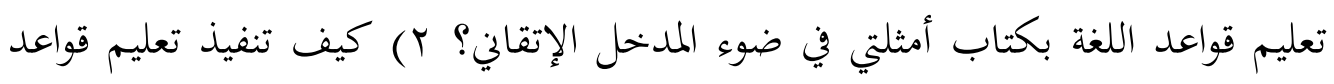

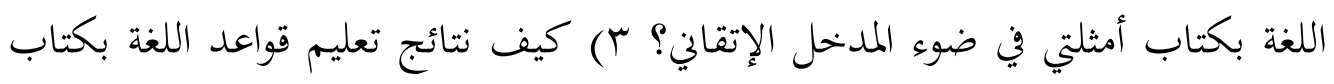

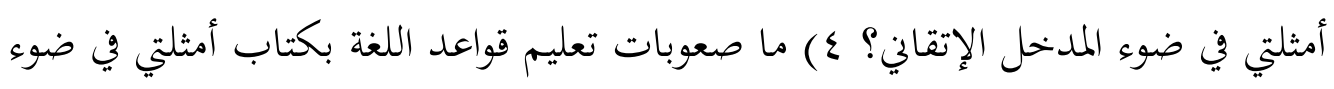

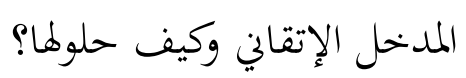

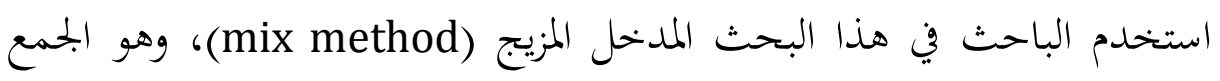

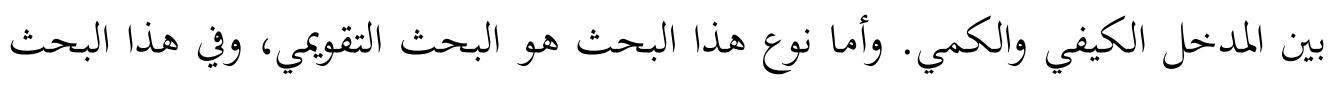

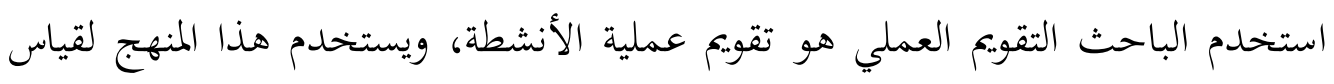


ومقارنة البرنامج بالأهداف المرجوة لاصدار الحكم عن قيمة برنامج التعليم واصلاح فعاليته المقبل. وللحصول على البيانات فيتصل الباحث بالخبراء باستخدام الطريقة المعاينة العمدية

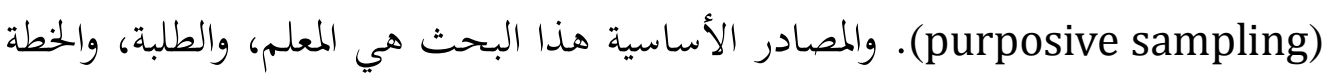
الدراسية، ودفتر نتائج التعليم، وعمليات التعليم والتقويم في الفصل. وعينة البحث هي

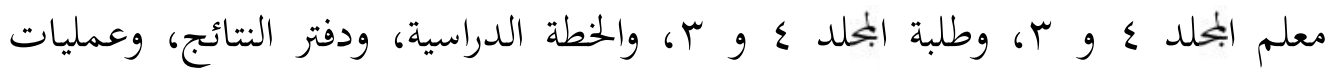
التعليم والتقويم في الصف الرابع والثالث. أما المصادر الإضافية هي رئيس برنامج أمثلتي وقسم التربية والكتب المدروسية والوثائق المتعلقة ببرنامج أمثلتي. أما الأساليب التي استخدمها الباحث لجمع البيانات فهي الملاحظة، والمقابلة، والإستبيان، والتوثيق. وبعد ما جمعت البيانات، استخدم الباحث المنهج التقويمي لتحليل البيانات من خلال تطبيق نموذج التقويم المنظومي (STAKE). وفي هذا البحث أراد الباحث أن يقيم فعالية تعليم قواعد اللغة بكتاب أمثلتي، فلذلك يستخدم الباحث البيانات الكيفية والكمية. تحليل البيانات الكيفية بالخطوات: عرض البيانات، وتصنيف البيانات وتبويبها، وتحليل البيانات وتفسيرها. أما تحليل البيانات الكمية من الاستبيان والوثيقة فهي بتحليل الوصفي المائوية.

\section{ب. عرض البيانات وتحليلها ومناقشتها}

يحاول الباحث هذا الفصل على تحليل البيانات ومناقستها عن تقويم تعليم قواعد اللغة بكتاب أمثلتي في معهد دار الفلاح. وكانت عملية التقويم في هذا البحث مستندة إلى التقويم البرنابجي بنموذج ستيك وهو بالمؤشرات التالية: (1) السياق، يتكون على بلى

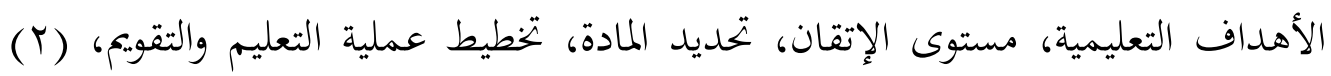
العملية، تتكون على تنظيم عملية التعليم، تنظيم الفصل، إتقان المعلم للمادة، أنماط التفاعل، فعال التلميذ، دافعية التعلم، تنفيذ التقويم التكويني والتقويم الختامي، (ب) النتائج، تتكون على نتائج التعلم بمستوى الإتقان المطلوبة. ا.تخطيط تعليم قواعد اللغة بكتاب أمثلتي في ضوء المدخل الإتقاني 


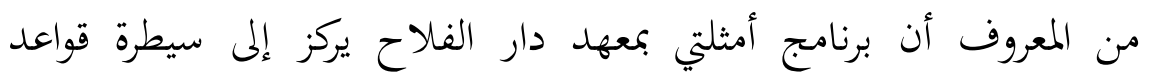

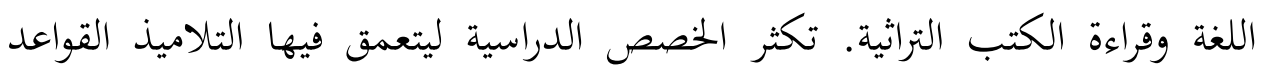
اللغوية. ومن ثم، أن النحو والصرف هي المواد الأساسية في تعليم اللغة العربية.

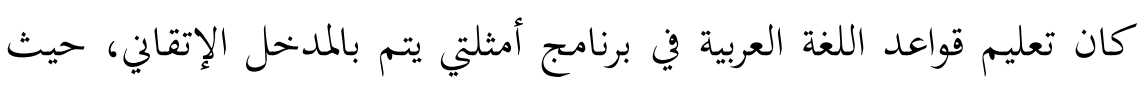

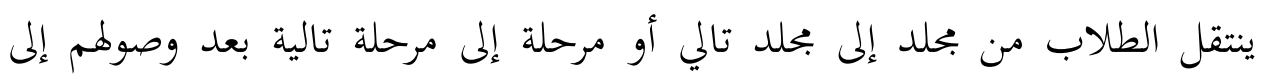

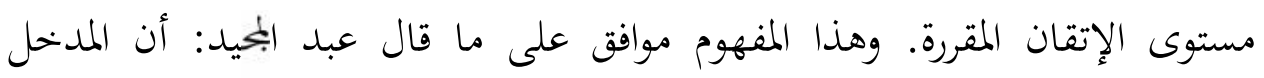
الإتقاني هو مدخل التدريس الذي يشرط للوصول إلى اتقان المتعلم اي كفاءات

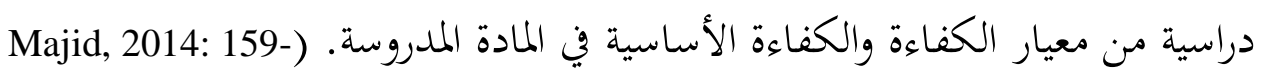

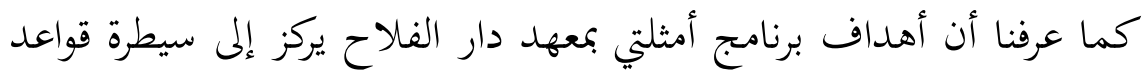

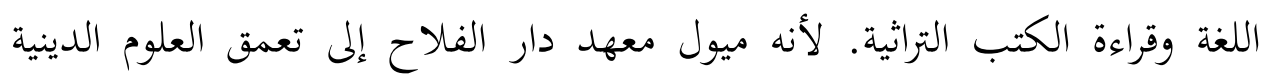

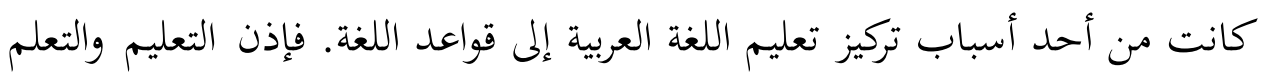

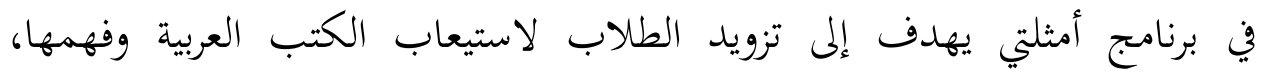

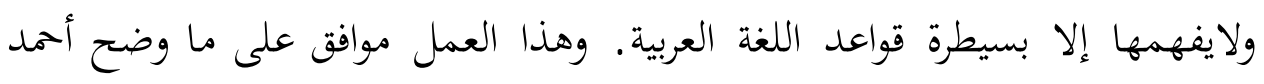

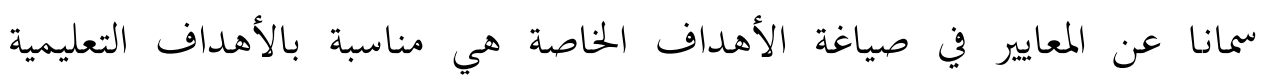

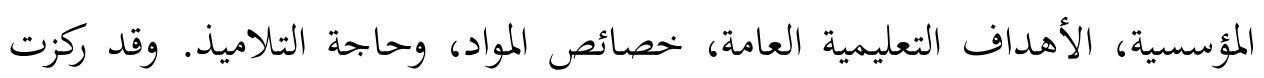

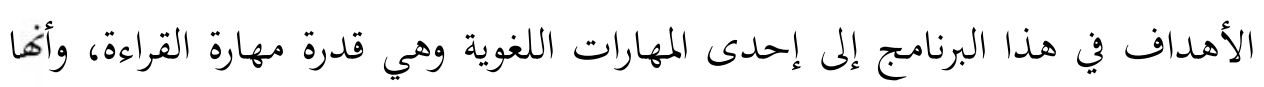

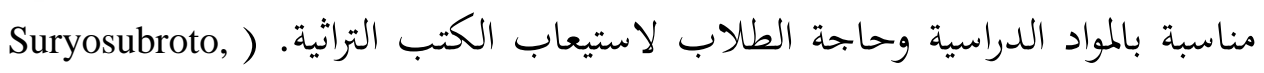
(2009: 26

بعد صياغة الأهداف المطلوبة، ينبغي أن تحدد مستوى الإتقان أولا قبل ابتداء

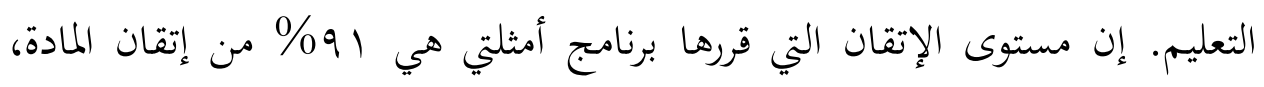

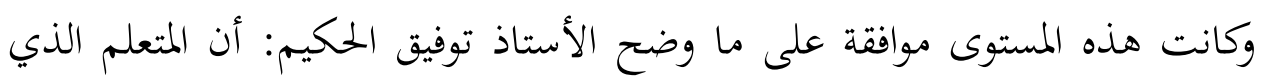




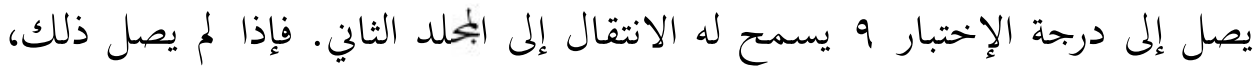

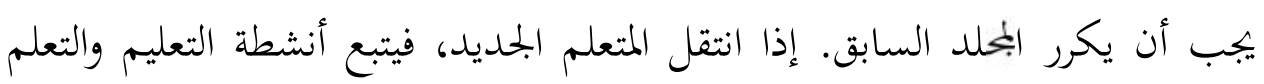
مباشرة ولو كانت في أثناء الدراسة. (Taufiq, 2004: 14)

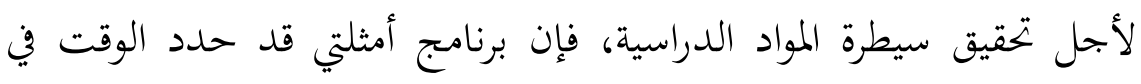

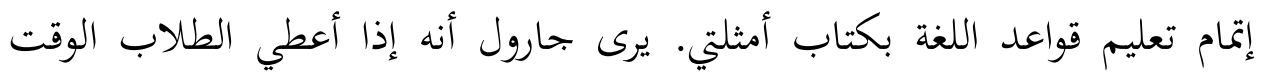

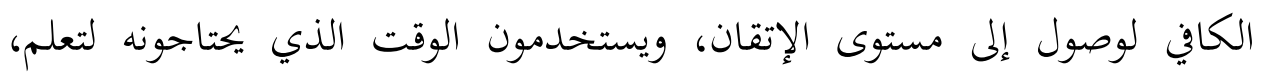
فسيحصلون على درجة إتقان الكفاءة. بل إلا يعطى الوقت الكافي ولايستخدمون

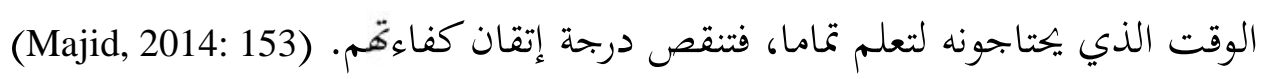

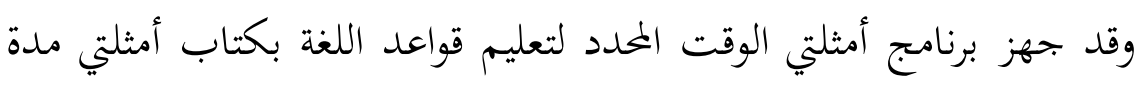

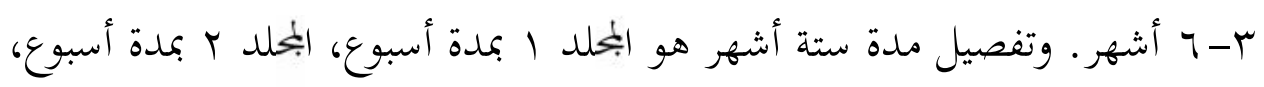

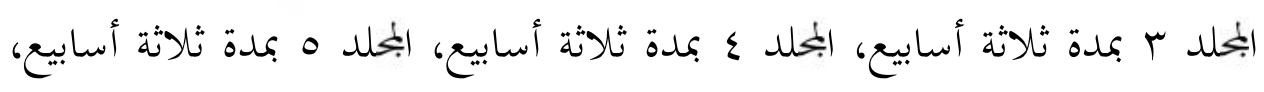

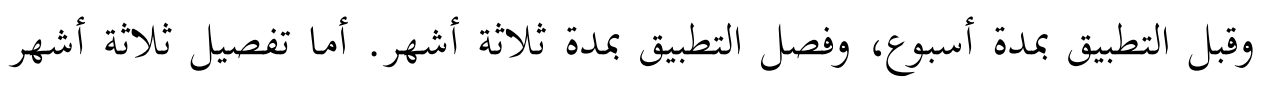

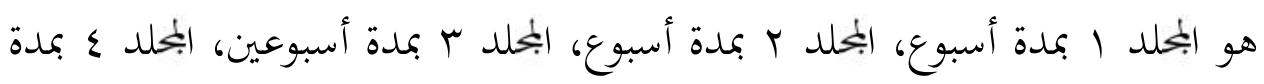

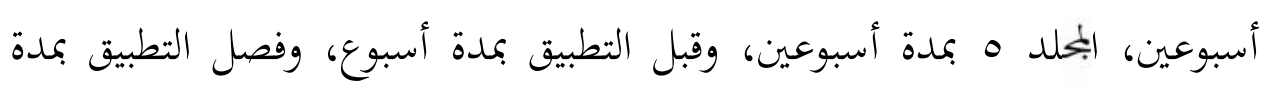

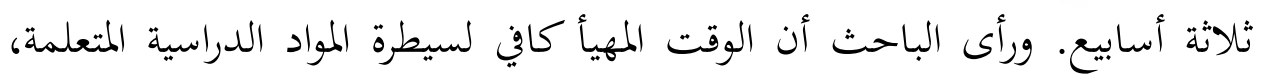

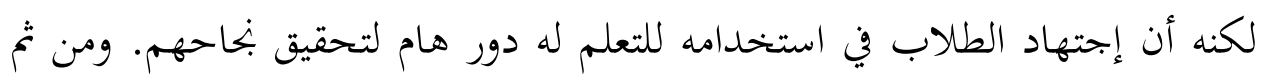

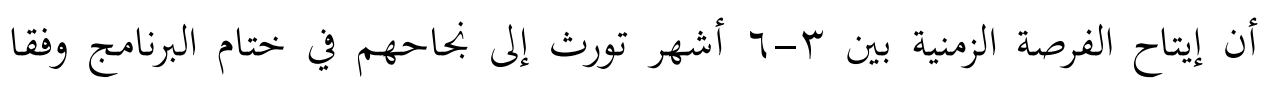

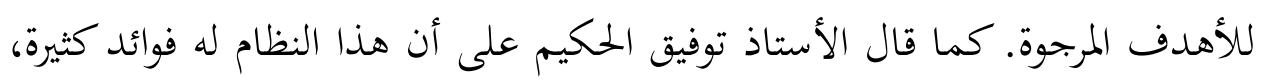

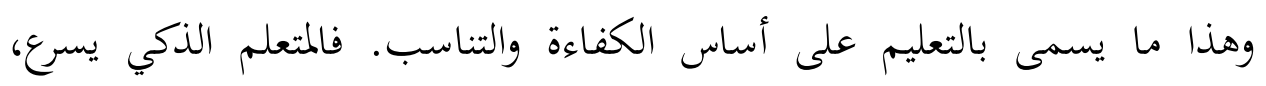
والمتعلم الجاهل ينضج. (Taufiq, 2004) بناء على أهداف تعليم اللغة العربية المواجهة إلى فهم الكتب العربية

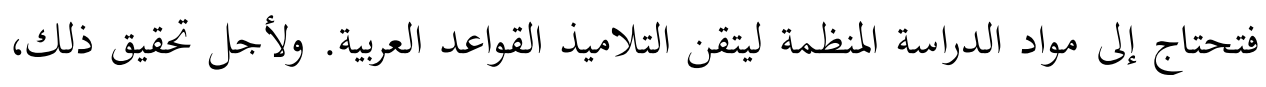


استخدم برنامج أمثلتي كتاب أمثلتي الذي ألفه الأستاذ توفيق الحكيم كالكتاب الأساسي في تعليم قواعد اللغة العربية. وكان تصميم كتاب أمثلتي بشكل بحلد،

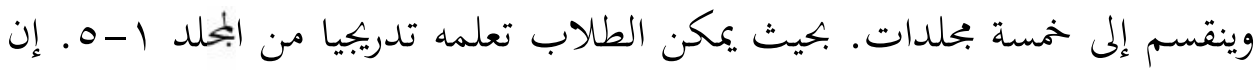
استخدام كتاب أمثلتي عند الباحث موافق على نظام التعلم الإتقاني بأن التعليم

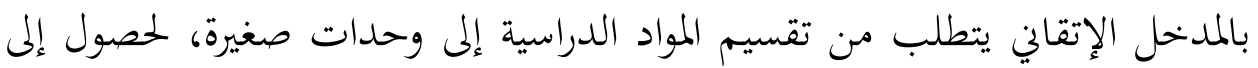
التغذية الراجعية وإصلاح النتائج بأسرع وقت ممكن. وينبغي أن ترتب الوحدات

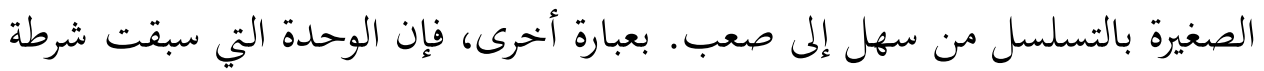
للوحدة التالية. (89-89) :Suryosubroto, 2009)

بشكل عام، أن برنامج أمثلتي ينقسم إلى ثلاث مستويات، وهي (1) مستوى البحلد، تشتمل على تعليم قواعد اللغة بكتاب أمثلتي كالكتاب الأساسي من البحلد 1-0، والكتاب المصاحبة من كتاب قاعدتي وخلاصة وصرفية وتتمة. (r) مستوى قبل التطبيق، هي الفصل لاستعداد الممارسة، وتمدف لتقوية الطلاب على تذكر المواد التي تم تحفيظها في مستوى البحلد. (r) مستوى التطبيق، هي الفصل لتطبيق جميع المواد الدراسية التي تم دراستها بالتدريبات نحو اعطاء المعنى والحركة والتركيب والبيان عن ذلك. وتهدف هذه المستوى ليكون الطلاب قادرين على قراءة الكتب التراثية. أما الكتاب المستخدم لأنشطة الممارسة هو كتاب التحرير والإبريز.

كتاب أمثلتي هو الكتاب الأساسي المبرمج والمصمم بإعداد بإعداد منهجي في أجزاء صغيرة، بحيث يمكن الطلاب تعلمه حسب قدرقم وسرعة فهمهم الفردية. تعتبر منهجيته بالنظر إلى ترتيب المحتوى التي يجب تعلمها تدريجيا ومتواصلا، حيث

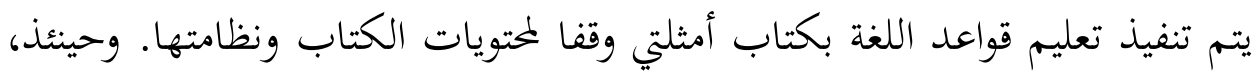
لايشتغل المعلم تحديد المادة قبل إلقاءها أثناء العملية التعليمية، وإنما يلقي المادة الموجودة في كتاب أمثلتي حسب منهجية الكتاب. ولهذا قد يكون التعليم لايجري 
حسب الفترة الزمنية المحددة، فينبغي على المعلم أن ينشئ الجدول لتحديد موضوعات

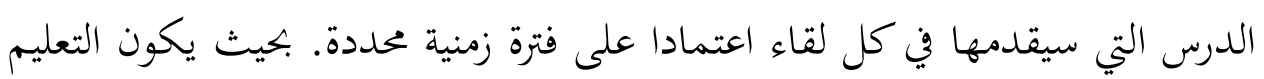
متسقا واتحاجيا وفقا للأهداف المطلوبة والفترة الزمنية المحددة.

لأجل تحقيق الأهداف ومستوى الإتقان المطلوبة، فيلزم إلى تخطيط طريقة التعليم. فإن طريقة التعليم المستخدمة في برنامج أمثلتي مناسبة بالأهداف والمواد المدروسة. المعلم هنا يستخدم طريقة أمثلتي حيث يلقي المعلم المادة الدراسية وتقديم

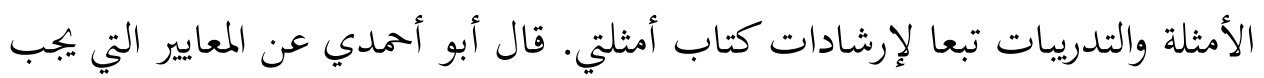
مراعتها عند إختيار الطريقة التعليمية، منها: (1) تناسب الطريقة بالأهداف، كان إنسان

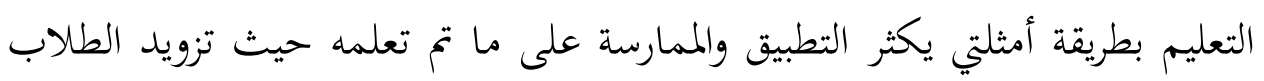

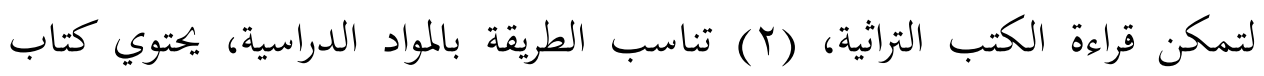
أمثلتي المعلومات والأمثلة والقواعد النظمية والتدريبات، لابد تقديمها بطريقة أمثلتي

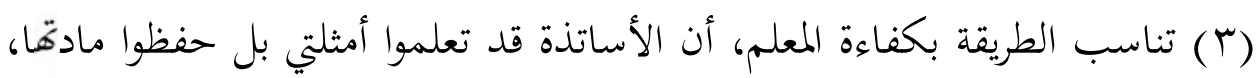
حيث يسهل تقديم المادة وإعطاء التوجيهات (ع) تناسب الطريقة بأحوال المتعلمين،

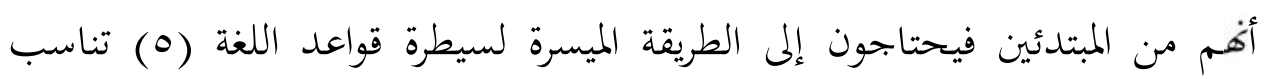

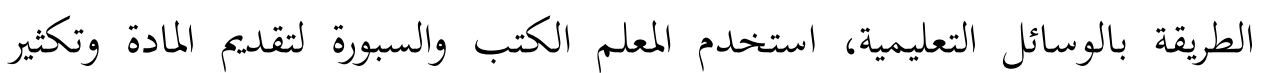
الأمثلة والتدريبات، بحيث يتم التعليم فعالا. (Suryosubroto, 2009: 28) وكان برنامج أمثلتي يركز على إتقان قواعد اللغة ومهارة القراءة، فعملية التقييم المصاغة لقياس نجاح التعلم باستخدام التقويم محكي المرجع، حيث يستخدمه المعلم في رئي

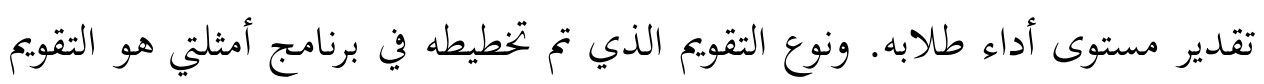

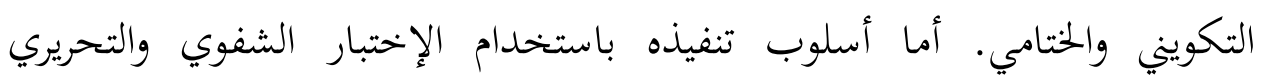
والعملي. هذا العمل موافق على تخطيط التقويم في التعلم الإتقاني أنه قبل تخطيط

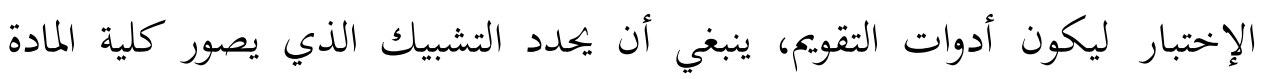


المدروسة في موضوع الدرس. وبالتالي تصميم أدوات التقويم لتحديد أية الأهداف التي لم يتقنها الطلاب والأهداف التي قد تم إتقاها. ويعتمد التقويم على المعايير، ويتم تنفيذه باستخدام التقويم التكويني والختامي، ليحصل المعلم على تغذية راجعة فورية وغالبية ومنهجية. (Suryosubroto, 2009: 91-92) بعد تنفيذ التقويم، سوف تعرف أية الأهداف التي تحققت بحاحها وما لم

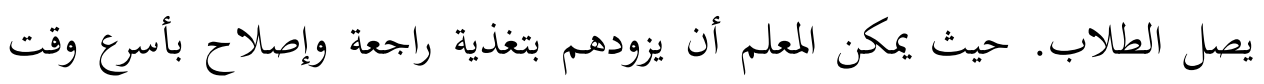

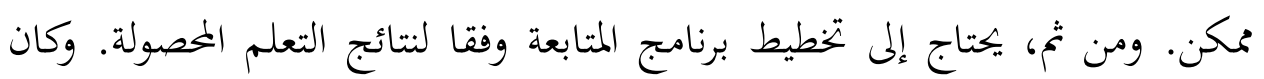

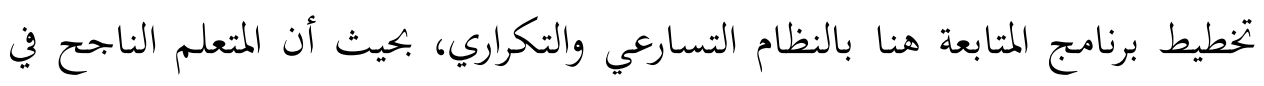
إمتحان البحلد يسمح له إنتقال إلى بحلد تالي مباشرة، أما الذي لم يحقق النجاح فعليه أن يكرر المادة من نفس البحلد حتى يتقنها تماما. وكذلك المتعلم الناجح في الإختبار

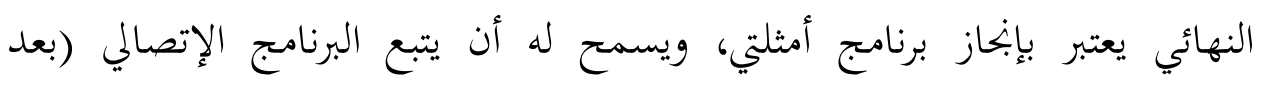

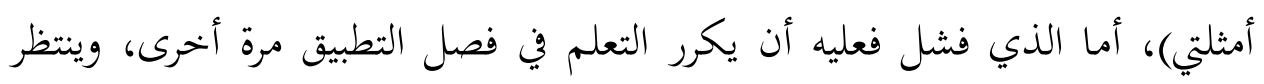
أداء الإختبار النهائي ثلاثة أشهر المقبلة. ץ.تنفيذ تعليم قواعد اللغة بكتاب أمثلتي

إن العملية التعليمية التي سيتم تنفيذها لوصول إلى الأهداف المرجوة، ينبغي

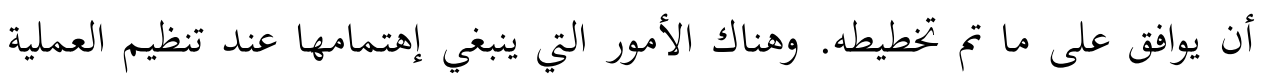

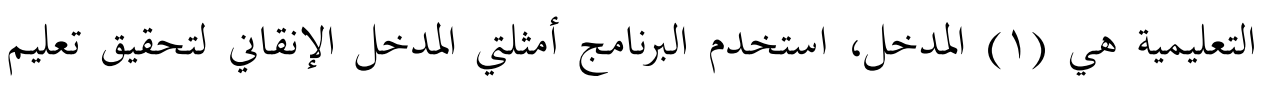

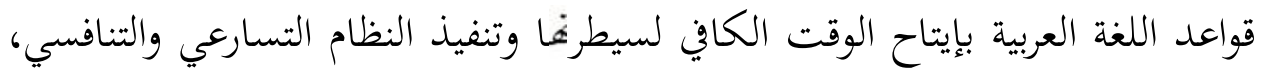

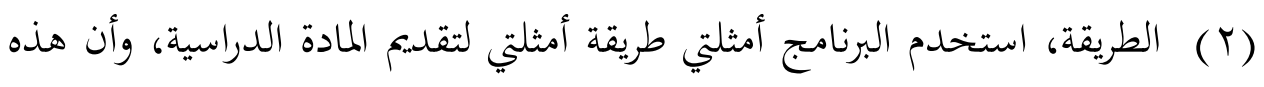
الطريقة مصممة من الطرائق التعليمية المتنوعة من المحاضرة والتحفيظ والتدريب والسؤال والجواب والتوظيف، (r) والإجراءات التعليمية، يبدأ تعليم قواعد اللغة بكتاب أمثلتي من مرحلة الاستعداد، مرحلة التدريس ومرحلة التقييم. 
رأء الباحث أن المدخل الإتقاني المستخدم في برنامج أمثلتي موافق على

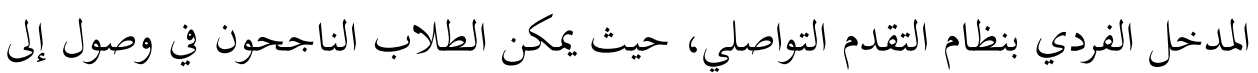

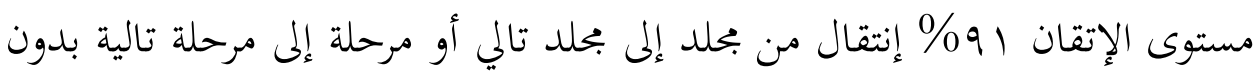

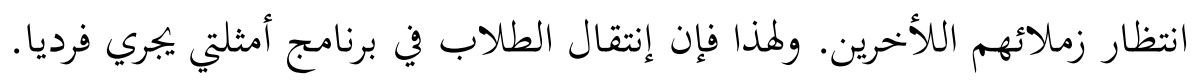

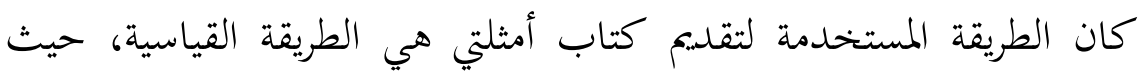

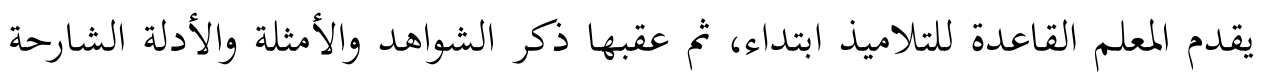

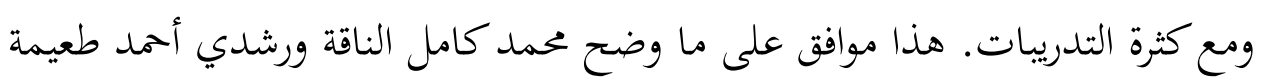

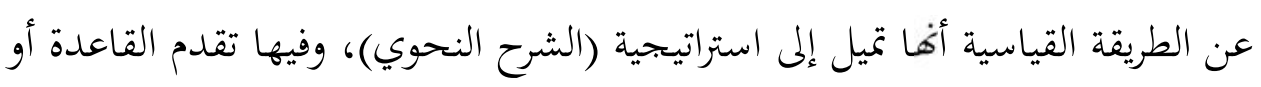

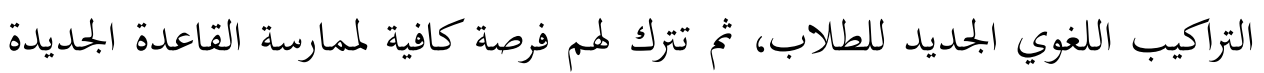

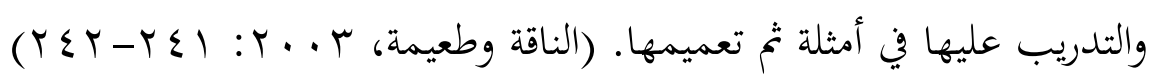

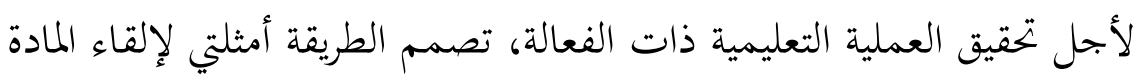

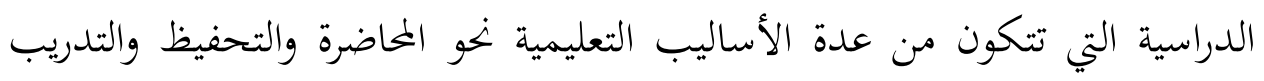

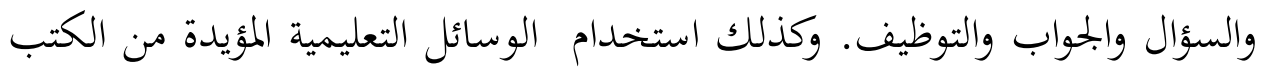

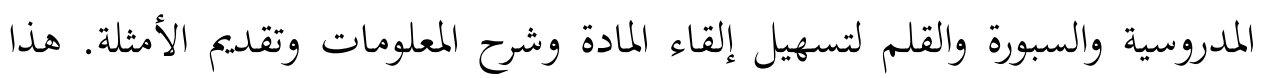

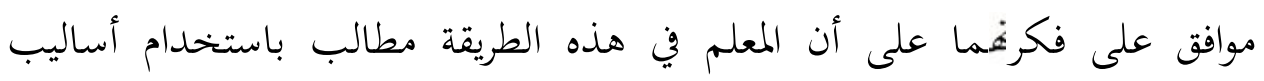

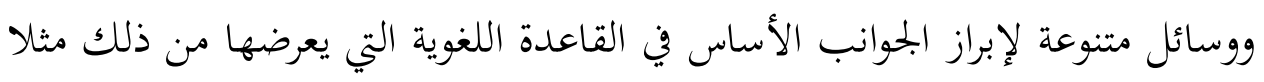

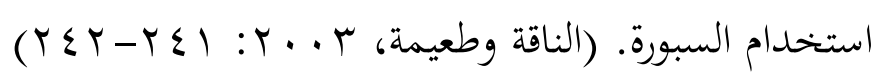

وتنقسم أنشطة التعليم والتعلم في برنامج أمثلتي إلى ثلاثة أقسم، هي إلقاء

المادة الدراسية وتغفيظ القواعد وأساسها النظمي وتطبيق المادئ المادة التي تم تعليمها.

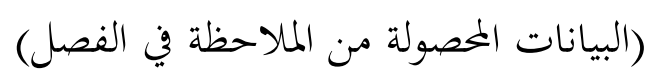

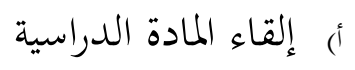


إن إلقاء مادة قواعد اللغة بكتاب أمثلتي ينقسم إلى ثلاثة مراحل كما حصل من

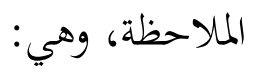

$$
\begin{aligned}
& \text { (1) مرحلة الاستعداد } \\
& \text { - يقرأ المعلم تحية السلام، ويقرأ المعلم الخضرة لمؤلف الكتاب وناشره } \\
& \text { - يشرح المعلم موضوع الدرس ويعلقه بالمادة السابقة } \\
& \text { r }
\end{aligned}
$$

- يلقي مادة قواعد اللغة ويقرأ الأمثلة التي لما علامة ( )، ويثتيك المعلومات

$$
\text { بقدر الحاجة }
$$

- يقرأ الطلاب الأمثلة من الأيات القرأنية جماعة، ويكرر قراءة المعلومات

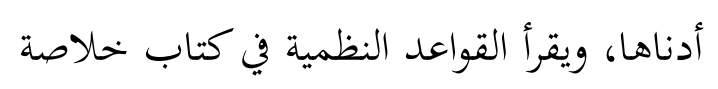

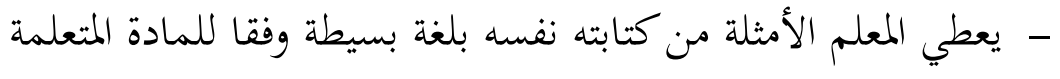

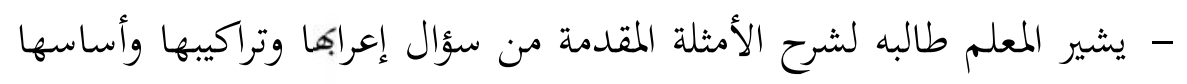

$$
\text { النظمي }
$$

- يتيح المعلم طلابه الفرصة ليسألوا عن المعلومات أو الأمثلة التي لم يتم فهمها

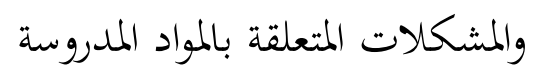

$$
\text { ب (ب مرحلة التقييم }
$$

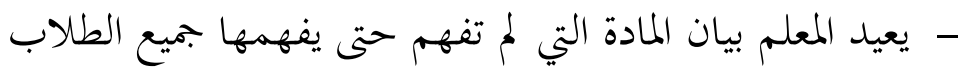

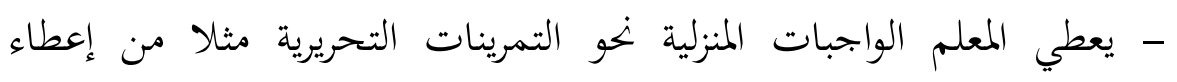

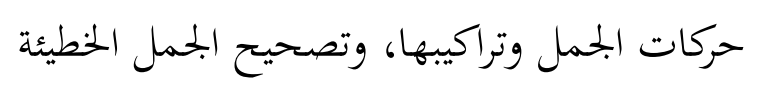

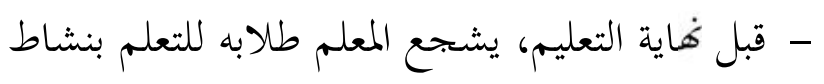


ب) تمفيظ القواعد وأساسها النظمي ويهدف تقديم التحفيظ لتحديد نوعية حفظ الطلاب على رمز القواعد وأساسه واسها

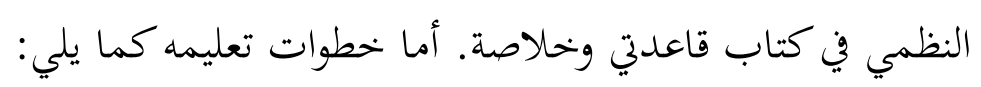
( ) يفتح المعلم الدرس ويقرأ التحية والحضرة

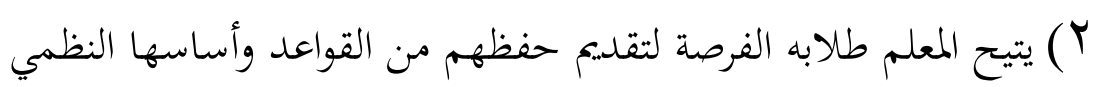

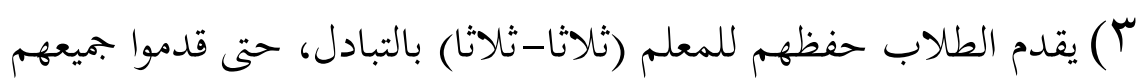

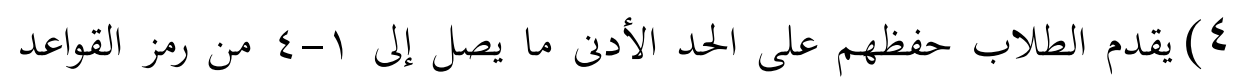
وأساسه النظمي لكل لقاء

0) المتعلم الذي لايقدم ذلك، فعليه عقاب نغو القيام في الصف وغيره

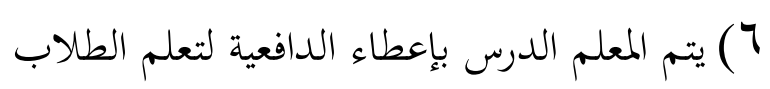
ت) تطبيق المادة

تستخدم أنشطة تطبيق أمثلتي لممارسة المادة التي تم تعلمها في الفرصة الدراسية صباحا بالتدريبات لتصحيح الجمل الخطيئة. وخطوات تعلمه كما يلي: لئل ( ) يفتح المعلم الدرس ويقرأ التحية والحضرة Y (Y) يكتب المعلم الجمل العربية من خمس أسئلة بكتابة خطيئة في السبورة

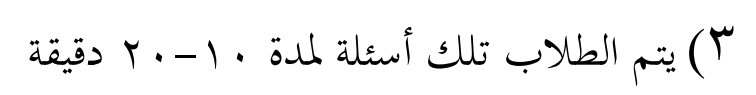

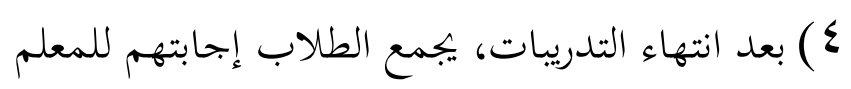

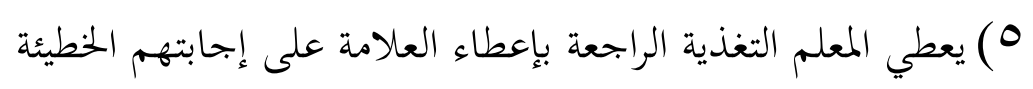

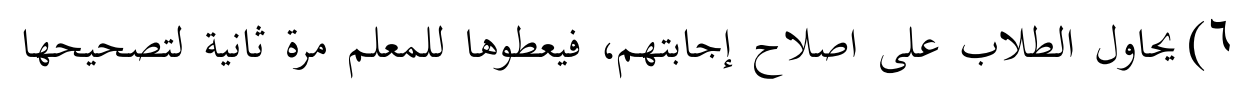
حتى تصححت إجابتهم كلها

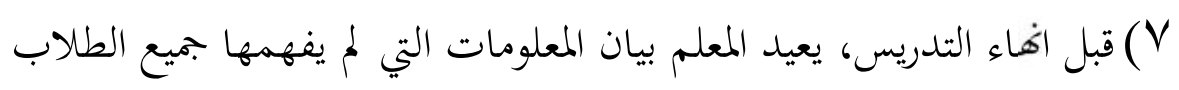


وكان تعليم قواعد اللغة الذي تم تنفيذه برنامج أمثلتي عند الباحث قد وافق على المعايير لتنظيم عملية التعليم، وهي (18 :Suryosubroto, 2009) : (1) توجيه التعليم لوصول إلى الأهداف، كان تناسب المدخل والطريقة وإجراءات التعليم المستخدمة لها دور هام لتسهيل الطلاب في ختام برنامج أمثلتي، فصار أن التعليم يوجه لوصول إلى الأهداف المطلوبة، (Y) استخدام الطريقة المناسبة وفقا لتخطيطها، إستخدم المعلم الطريقة القياسية لتقديم المادة الدراسية والتمرينات والتطبيقات لتسهيل الطلاب على سيطرتما تماما، (r) استخدام الطريقة البديلة، يمكن تقديم كتاب أمثلتي بإحدى الطرائق التعليمية من المحاضرة والتحفيظ والتدريب والسؤال والجواب والتوظيف، حيث يعلم تلاميذه بأسلوب مرونة حسب الحاجة، (ع) تنفيذ خطوات

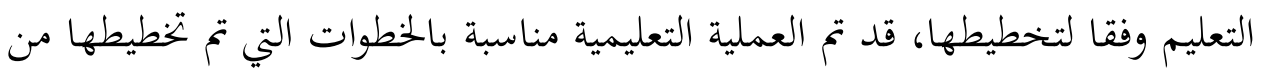
المرحلة الاستعداد ومرحلة التدريس ومرحلة التقييم. لأجل تحقيق بنحاح التعليم، يحتاج إلى تنظيم الفصل لتكوين الظروف التعليمية الأمثل، حيث يتعلم الطلاب بتركيز وراحة داخل الفصل. ويعتبر نجاح تنظيم الفصل (1) : (Suryosubroto, 2009:41) (4) الذي تم تنفيذه في برنامج أمثلتي بالمعايير، منها تكوين مناخ الفصل المريح، يحاول المعلم على تكوين ظروف الفصل المريحة للتعلم

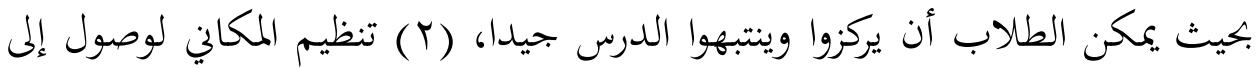
الأهداف، نظم المعلم والطلاب الفصل وأعدوا معا قبل إبداء التدريس من تنظيف الغرفة ومسح السبورة وغيرها، (r) موقف العدالة في توزيع الأسئلة، يقف المعلم

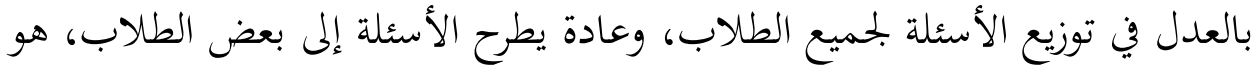
الذي ينعس في الفصل ولايهتم بالدرس، (ع) الدقة في إبداء الدرس وإنهاءه، بتري عملية التعليم والتعلم حسب الجمدول الدراسي المحدد، ولكنه في بعض الاحيان تأجل التعليم، لأن المعلم مشغول لحث الطلاب الكسالى أن يدخلوا الفصل قبل إبداء 
التدريس. ولهذا، فإن تنظيم الفصل الذي تم تنفيذه في برنامج أمثلتي عند الباحث قد تم فعالا لتكوين الظروف التعليمية المثالية.

ومن علامات التعليم بالمدخل الإتقاني هي استخدام مبداء التعلم الفعال.

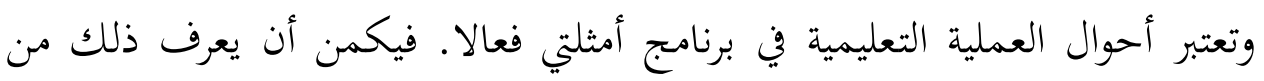
فعال الطلبة عند مشاركتها داخل الفصل بالمعايير التالية، منها (Sudjana, 2011:61): (1) مشاركة الطلاب في عملية التعليم والتعلم، أن الطلاب في برنامج أمثلتي يشاركون

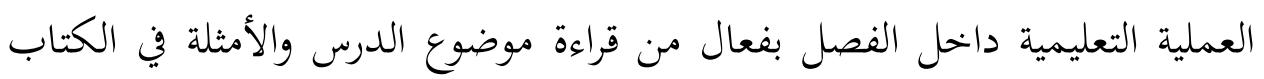

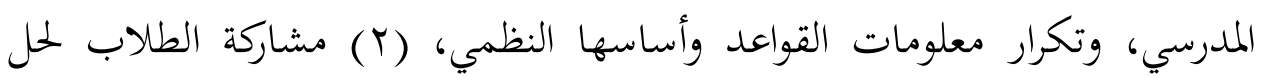

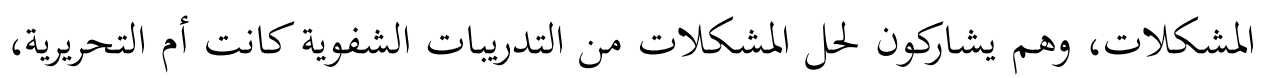

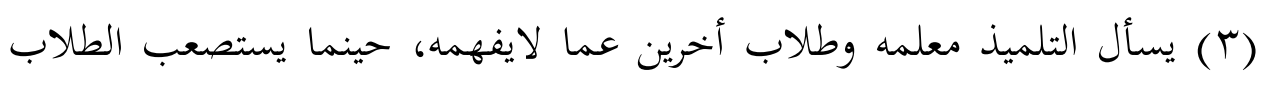

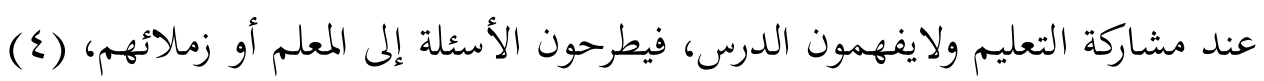

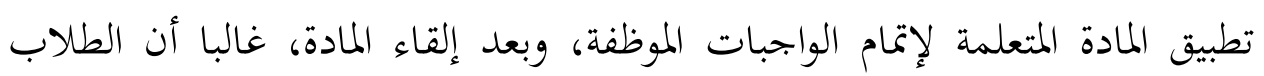

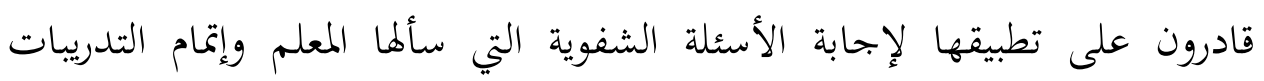
الموظفة.

لاشك أن التعليم الجيد يجب أن يحرك دافعية الطلاب بحيث يجتهدوا عند

التعلم. الدافعية التي يقصدها الباحث هنا وهي التي تصدر من نفس التلاميذ، حيث

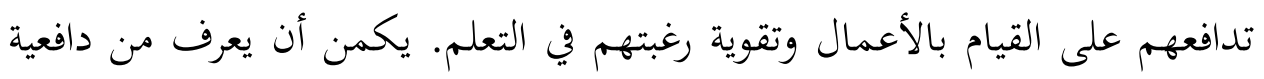

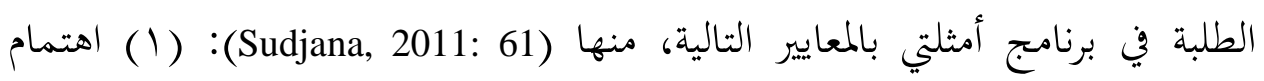
الطلاب وانتباههم بالدرس، أن لتلاميذ برنامج أمثلتي إهتمام كبير بتعلم قواعد اللغة

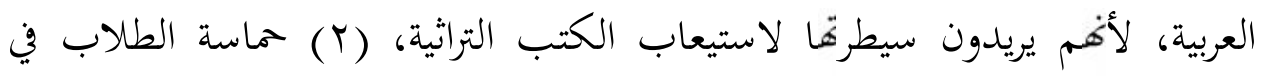
اتباع العملية التعليمية، لهم حماسة واجتهاد عند مشاركة العملية التعليمية داخل الفصل، ويتضح ذلك على أهم قد دخلوا الفصل قبل دخول المعلم، وينتبهون كل 
مرحة من مراحل تعليم كتاب أمثلتي، ويجتهدون في تحفيظ رمز القواعد وأساسه

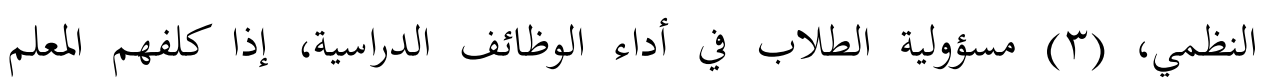

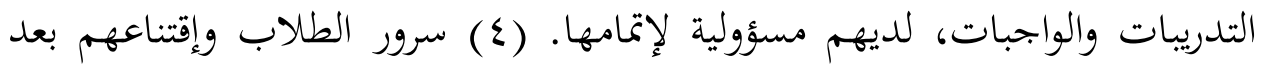

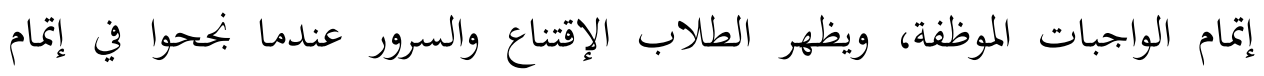
الواجبات بنتيجة جيدة، إن كانت إجابتنا لاتزال مخطيئة، فيحاولون على تصحيحها.

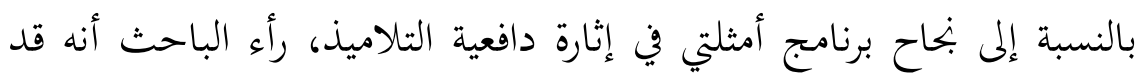

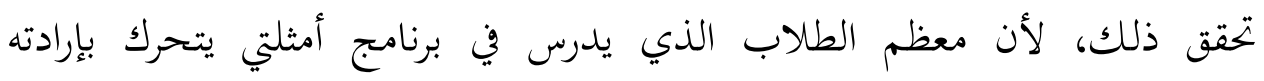
الداخلية، وأن المعلم لايزال أن يعطيهم الدافعية أثناء عملية التعليم والتعلم بالمكافأة

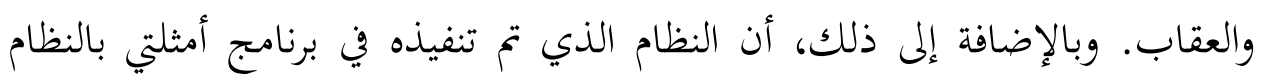
التسابقي والتنافسي، لما دور كبير لإثارة وتحريك دافعيتهم للتعلم.

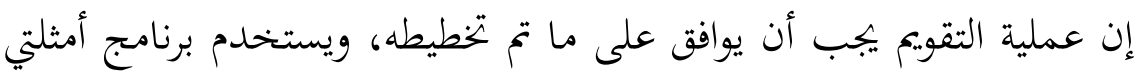
التقويم التكويني والختامي لتحديد استيعاب الطلاب بعد مشاركة العملية التعليمية.

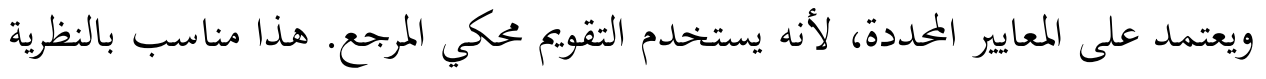
عن أداء التقويم في التعلم الإتقاني أنه يتم تقييم نتائج التعليم بالمدخل الإتقاني التحاني

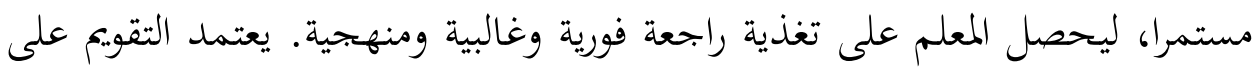
المعايير، ويتم تنفيذه باستخدام التقويم التكويني والختامي. (Suryosubroto, 2009: 87)

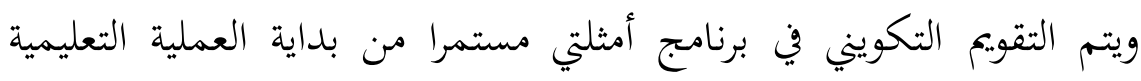

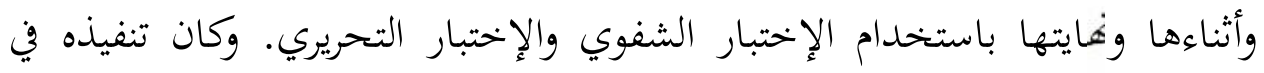

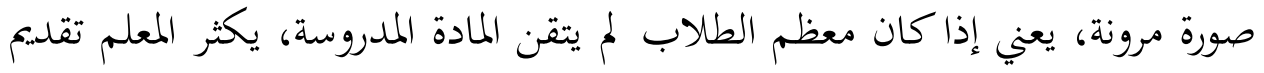
الأمثلة والتدريات شفوية كانت أم تحريرية. وبعد تنفيذ التقويم، يزودهم المعلم بتغذية الماتية راجعة على ما يستصعبونه وما لم يتقنوه حتى يفهم الطلاب جميعهم. 
وكان التقويم الختامي يعتمد على المعايير التي تم تحديدها من قبل المعهد

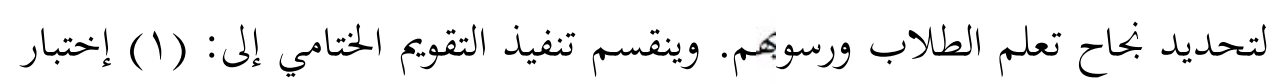

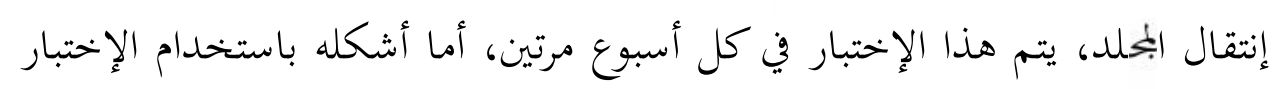

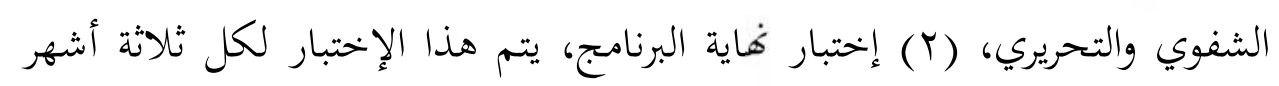

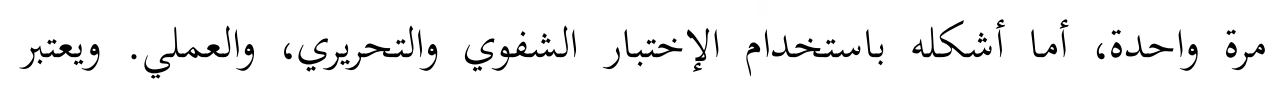

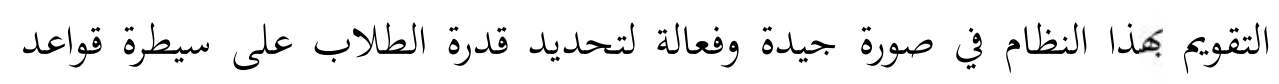

$$
\text { ك. بنتائج تعليم قواعد اللغة بكتاب أمثلتية واستيعاب الكتب التراثية. }
$$

وبعد تنفيذ العملية التقويمية سوف يكصل على المخرجات التعليمية، ويقصد

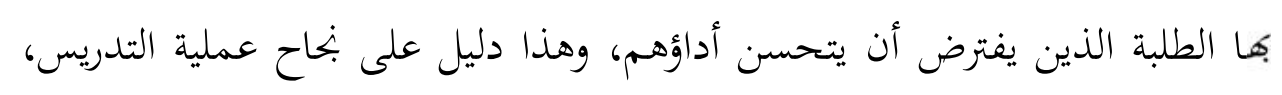

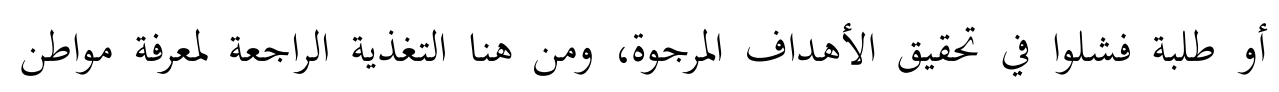

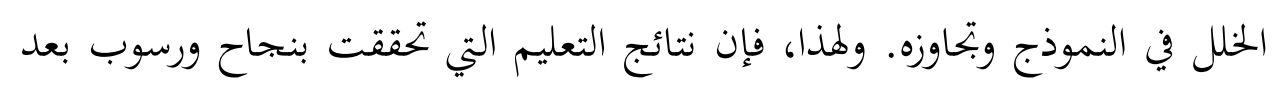
تنفيذ الأنشطة التعليمية معيار لمدى فعالية العملية التدريسية التي تم تنفيذها.

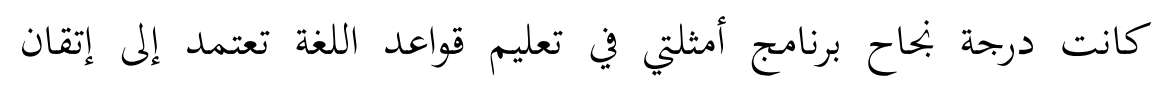

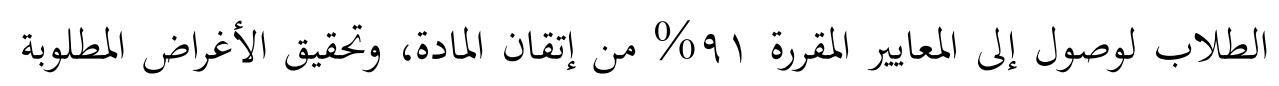

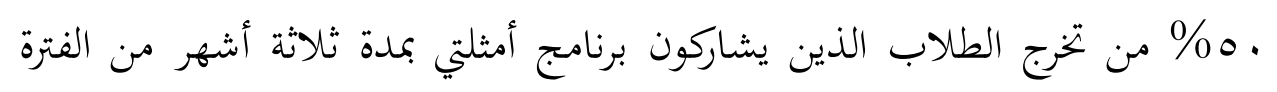

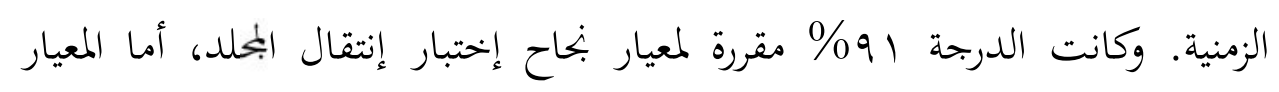

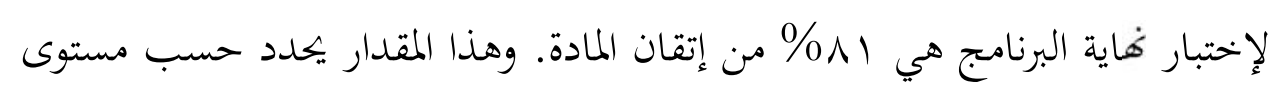

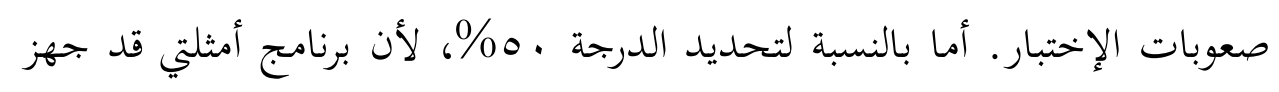

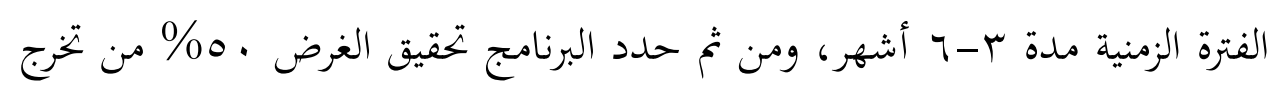

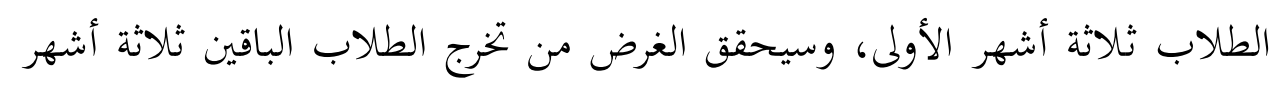


المقبل. حيث يهقق النجاح الطلاب في ختام البرنامج جميعهم مدة ستة أشهر كاملة

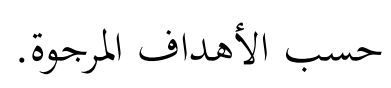

ونتائج التعليم المصصولة بعد مشاركة الطلاب العمليات التعليمية في برنامج أمثلتي قد تحققت النجاح. ويتضح ذلك بالنظر إلى نتائج تعلم الطلاب في إختبار

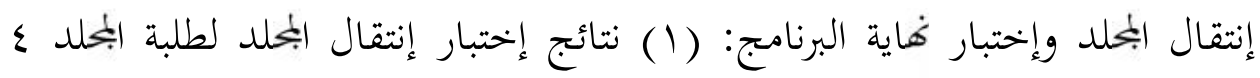

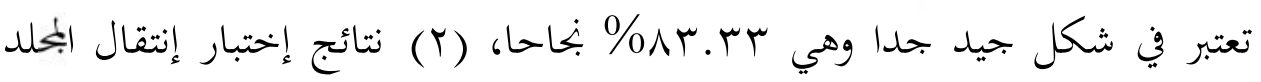

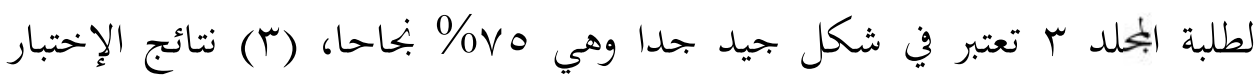

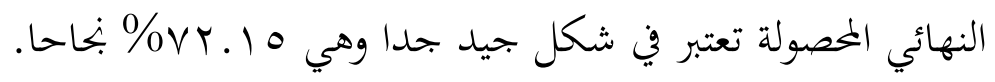

\section{ع.صعوبات تعليم قواعد اللغة بكتاب أمثلتي وحلولها}

إن برنامج أمثلتي الذي تم تنفيذه في معهد دار الفلاح يواجه بعض الصعوبات

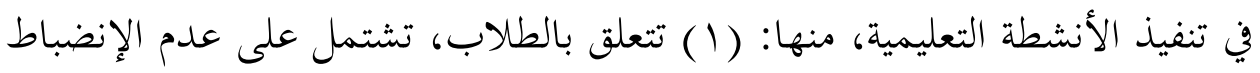
في مشاركة الأنشطة التعليمية، وعدم إهتمامهم بالدرس لكسل، ولديهم خلفية وقدرة مبدائية مختلفة، وصعوبة تحفيظ القواعد وأساسها النظمي، وعدم التكيف في المعهد بحيث لايركزوا عند مشاركة العملية التعليمية جيدا، (r) تتعلق بالإداريين، تشتمل على تنفيذ التدريس المكرر بالمادة والطريقة متساويين بحيث يشعر الطلاب بالملل

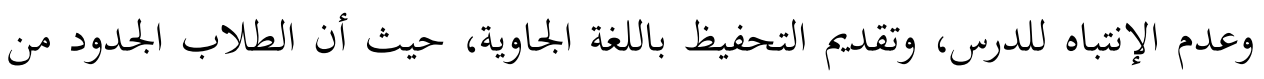
خارج الجاوى يستصعبون في فهمها وتحفيظها. أما الحلول التي بذلتها إدارة البرنامج لمعالجتها تشتمل على: (1) تنفيذ تقييم الأداء لكل أسبوع مرة واحدة، الذي تم تنفيذه الإداريون وبحلس الأساتيذة لمناقشة أحوال الأنشطة التعليمية والصعوبات التي تواجهها الطلاب وصياغة السياسات المناسبة لمعالجة تلك الصعوبات، (Y) تنفيذ برنامج قبل أمثلتي ودراسة تلاوة القرأن الكريم، لتزويد الطلاب الذين لم يستكملوا الشروط من دخول برنامج أمثلتي 
بالتوجيهات الخاصة حسب الحاجة من تعليم القراءة والكتابة مثلا، (ب) صياغة النظام المناسبة من تنفيذ نظام النقاط لمخالفه، بحيث يمكن الطلاب أن يكونوا منضبطين إلى انصياع النظام، (ع) إعطاء الدعم والتحفيز من خلال التقرب بالصبر

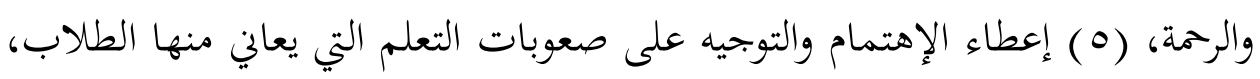
(7) إعطاء العقاب للطلاب الكسالى وعدم الإنضباط حسب خطيئهم، يعاقب

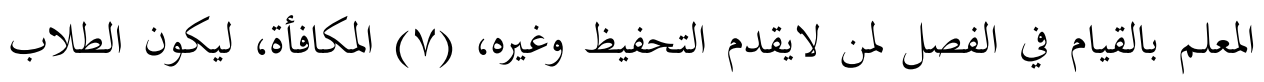

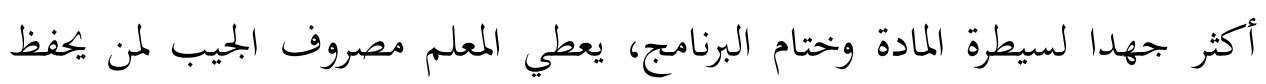
القواعد وأساسها النظمي بسرعة وسلاسة وغيره.

ج. ت ع الخلاصة

بناء على نتائج البحث المحصولة في تقويم تعليم قواعد اللغة بكتاب أمثلتي في ضوء المدخل الإتقاني في معهد دار الفلاح تدل على فعالة. مستندا إلى التقويم البرنابجي، وهو السياق (تخطيط التعليم)، العملية (تنفيذ التعليم)، والنتائج (نتائج التعليم). من ناحية تخطيط تعليم قواعد اللغة الذي تم صياغته في برنامج أمثلتي فيعتبر جيدا، لأنه مناسب بالمدخل الإتقاني. ويتجلى ذلك بالنظر إلى: (1) الأهداف التعليمية،

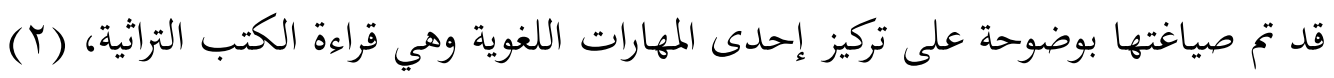

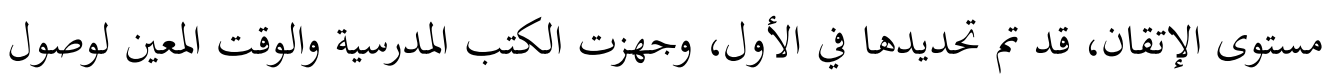

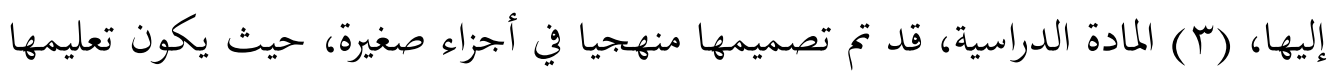
تدريجيا حسب ترتيب الكتاب، (ع) تخطيط التعليم، كانت طريقة التعليم وإجراءاته التي تم تخطيطها مناسبتين بالأهداف والمواد الدراسية، (0) تخطيط التقويم، كانت لجنة الإختبار ونوعه وأداته وموعد تنفيذه وبرنامج المتابعة قد تم تخطيطها بوضوحة وتواصلة، حيث يمكن بكن تزويدهم بتغذية راجعة وإصلاح بأسرع وقت مككن. 
من ناحية تعليم قواعد اللغة الذي تم تنفيذه في برنامج أمثلتي سواء كان متعلقا

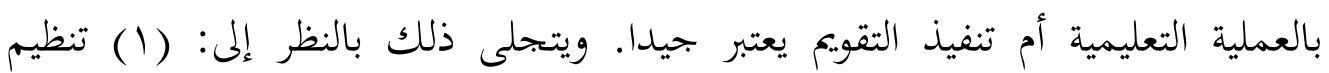

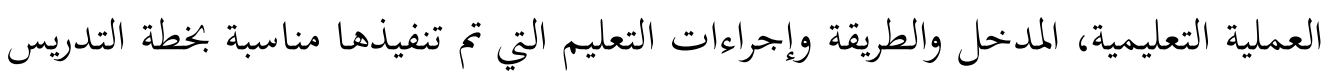
وموجهة لتحقيق الأهداف المطلوبة، (r) تنظيم الفصل، قد تم تنفيذه فعالا لتكوين

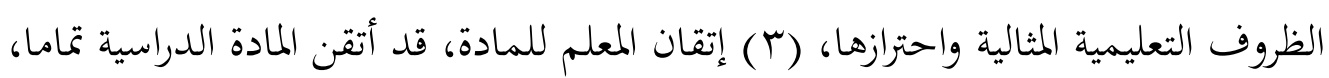

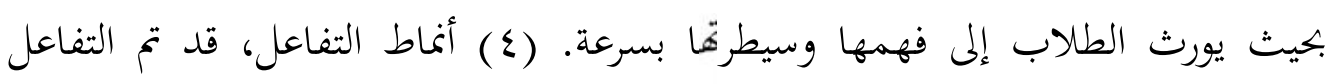
التعليمي فعالا ومرونا حسب الحاجة، يعطي المعلم التوجيه والتحفيز لتعلم، ويتيحهم

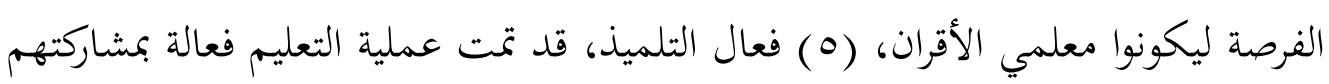

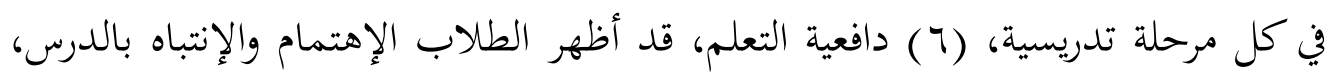
والحماسة عند مشاركة العملية التعليمية، والمسؤولية في إتمام الواجبات الموظفة والإقتناء بعد إتمامها بنجاح. ويتجلى بناح تنفيذ التقويم بالنظر إلى (1) التقويم التكويني، قد تم تنفيذه

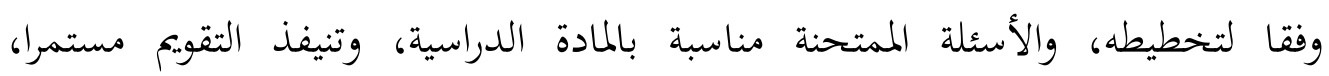
وتزويدهم بتغذية راجعة على نتائج التعليم الخحصولة. (r) التقويم الختامي، قد تحققت الإختبارات مناسبة بتخطيطها، ووجود التناسب بين الأسئلة والمادة الدراسية المتعلمة، ووجود تقرير حصيلة التقييم في شكل SKHU وبرنامج المتابعة بعد تنفيذ عملية التقويم. ومن ناحية نتائج التعليم المحصولة بعد مشاركة الطلاب العمليات التعليمية في

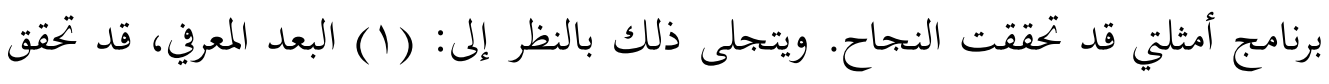

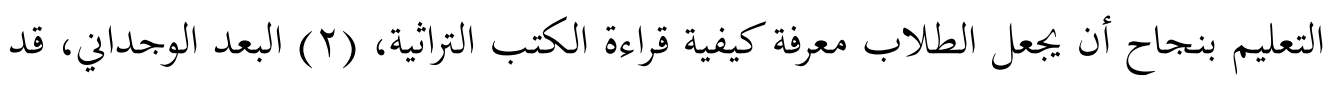
تحقق التعليم بنجاح أن يجعل الطلاب مسرورين في تعلم قواعد اللغة وتنمية حماستهم لإتمام

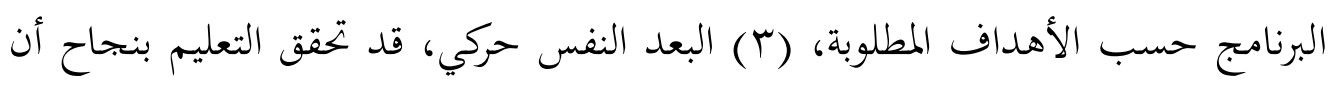
يجعل الطلاب قادرين على تطبيق ما تم تدريسه لإنجاز الواجبات الموظفة. ويتضح نجاح برنامج أمثلتي أكثر ملموسا، بالنظر إلى نتائج تعلم الطلاب في إختبار إنتقال البحلد 
وإختبار فهاية البرنامج: (1) نتائج إختبار إنتقال المحلد لطلبة المحلد ع تعتبر في شكل جيد

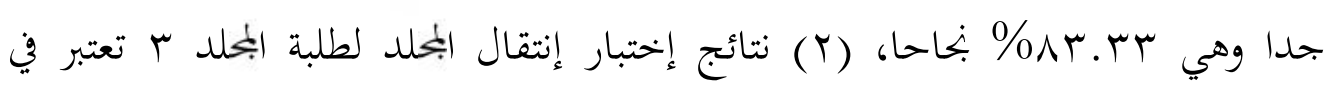

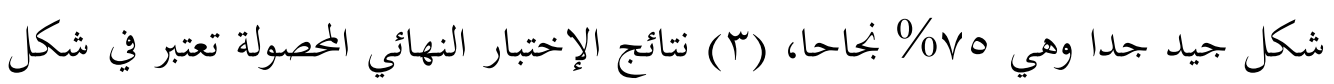

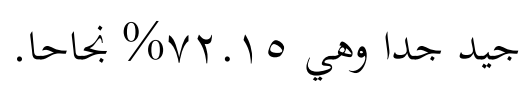

وكان تنفيذ تعليم قواعد اللغة بكتاب أمثلتي في معهد دار الفلاح تبقي بعض الصعوبات، منها: (1) تتعلق بالطلاب، تشتمل على عدم الإنضباط والكسل والمدخلات

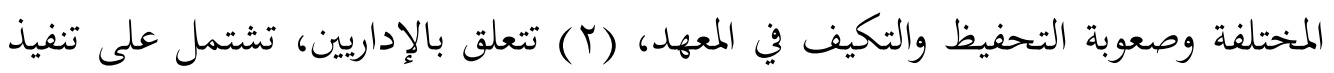
التدريس المكرر بالمادة والطريقة متساويين، وتقديم التحفيظ باللغة الجاوية. والحلول التي

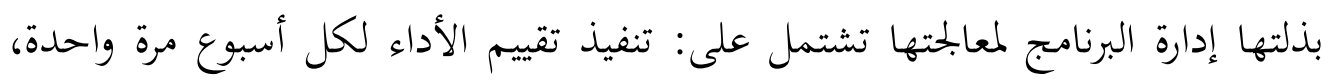
تنفيذ برنامج قبل أمثلتي، صياغة النظام المناسبة، إعطاء الدعم والتحفيز، إعطاء الإهتمام والتوجيه، إعطاء العقاب والمكافأة. 


\section{قائمة المراجع}

أحمد، عبد القادر. أ IV7 ا ـ طرق تعليم اللغة العربية. الطبعة الثالثة. القاهرة: مكتبة النهضة المصرية.

الناقة، محمد كامل ورشدي أحمد طعيمة. ب . . r . طرائق تلديس اللغة العبية لغير الناطقين بها. إيسيسكو.

المالاحظة على إجراءات التعليم في الفصل بمعهد دار الفلاج جفارا، التاريخ ه 1 مارس إلى ع

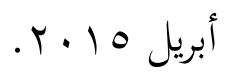

Hakim, Taufiqul. 2003. Amtsilati Metode Praktis Mendalami Al-Qur'an dan Membaca Kitab Kuning. Cet. 2. Jepara: Ponpes Darul Falah.

Hakim, Taufiqul. 2004. Tawaran Revolusi Sistem Pendidikan Nasional Berbasis Kompetensi. Cet. 1. Jepara: Ponpes Darul Falah.

Majid, Abdul. 2014. Strategi Pembelajaran. Bandung: Remaja Rosdakarya.

Sudjana, Nana. 2011. Penilaian Hasil Proses Belajar Mengajar. Bandung: Remaja Rosdakarya.

Suryosubroto, B. 2009. Proses Belajar Mengajar di Sekolah. Jakarta: Rineka Cipta. 